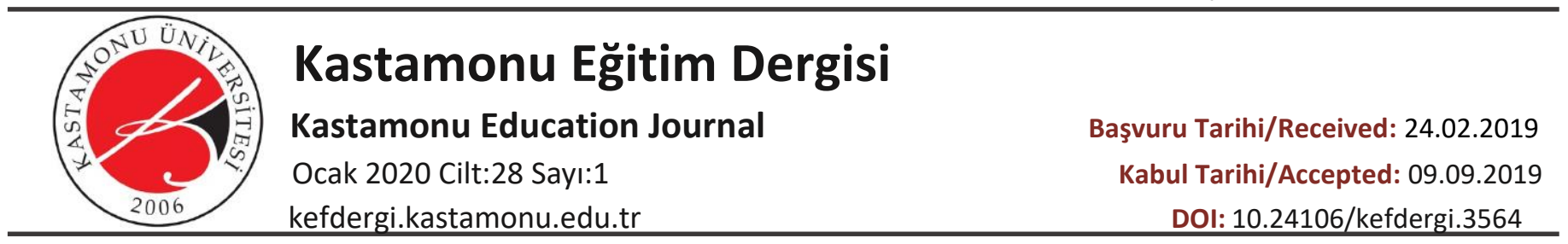

\title{
Oturarak Voleybol Oyuncularının Öz Güven Düzeylerinin Tespiti
}

\section{Determining the Self-Confidence Levels of Sitting Volleyball Players}

\author{
Öz \\ Atike YILMAZ ${ }^{1}$, Hüseyin KIRIMOĞLU²
}

Bu araştırma, Türkiye Bedensel Engelliler Spor Federasyonu, Oturarak Voleybol oyuncularının özgüven düzeylerini tespit etmek amacına odaklanmıştır. Katılımcıların öz güven düzeylerini belirlemek için araştırmacılar tarafından geliştirilen "Kişisel Bilgi Formu" ve Akın (2007) tarafından geliştirilen "Öz Güven Ölçeği” kullanılmıştır. Çalışmada genel tarama modeli kullanılmıştır. Araştırma grubu, Türkiye Bedensel Engelliler Spor Federasyonu tarafında Alanya ilinde düzenlenen Bedensel Engelliler Oturarak Voleybol Müsabakalarına katılan genel toplamda 92 bedensel engelli sporcu içerisinden çalışmamıza gönüllü olarak katılmayı kabul eden, 52'si erkek, 6'sı kadın olmak üzere genel toplamda 58 oturarak voleybol oyuncusundan oluşmuştur. Verilerin analizinde MannWhitney $\mathrm{U}$ ve Kruskal Wallis $\mathrm{H}$ testleri kullanılmıştır. Elde edilen verilere göre, kardeş sayısı, algılanan gelir düzeyi, lisans yaşı açılarından, oyuncuların öz güven düzeylerinin istatistiksel açıdan anlamlı farklılık oluşturmadığı tespit edilirken, katılımcıların cinsiyetleri ile iç özgüven düzeyleri ortalamaları arasında anlamlı farklılık tespit edilmiştir. Yine katılımcıların, cinsiyetleri ile dış özgüven düzeyleri ortalamaları arasında anlamlı farklılık bulunmuştur. Katılımcıların farklı bir spor branşı ile uğraşma durumu açısından faklı bir spor branşı ile uğraşanların iç öz güven düzeyleri, uğraşmayanlara oranla anlamlı düzeyde yüksek bulunmuştur. Buna karşın dış öz güven seviyelerinde anlamlı farklılık tespit edilememiştir. Ancak genel öz güven puanları açısından, farklı bir spor branşı ile uğraşan katılımcıların, genel öz güven düzeyi, farklı bir spor branşı ile uğraşmayanlara oranla anlamlı düzeyde farklılık göstermiştir $(p<0,05)$. Sonuç olarak, erkek katılımcıların, kadın katılımcılara oranla daha yüksek iç ve dış özgüvene sahip olduklarını, farklı spor branşı ile uğraşmanın iç öz güven düzeyini arttırdığını ve spor yapmanın bedensel engelli bireylerde öz güven düzeyine pozitif katkı sağlayabileceğini söyleyebiliriz

Anahtar Kelimeler: oturarak voleybol, öz güven

\section{Abstract}

This research focuses on determining the level of self-confidence of sitting volleyball players of The Turkish Sports Federation for the Physically Disabled. The "Personal Information Form" developed by the researchers and the "Self-Confidence Scale" developed by Akın (2007) were used in the study. The study group was consisted of 58 sitting volleyball players in total; 52 male, 6 female, who agreed to participate voluntarily from a total of 92 physically challenged athletes who participated in Physically Disabled Sitting Volleyball Competitions organized by in Alanya province. In the evaluation of the data analysis was used. MannWhitney $\mathrm{U}$ and Kruskal Wallis $\mathrm{H}$ tests. According to the data, while it was determined that there was no statistically significant difference in the self-confidence levels in terms of the number of siblings, perceived income level and license age, there was a significant difference between participants' genders and levels of inner self-confidence. There was also a significant difference between the participants' genders and external self-confidence levels. In the external self-confidence, male participants reported higher levels of external self-confidence. Another finding from the study was that the inner self-confidence levels of participants, who deal with another sports branch, were significantly higher than those who doesn't. However, no significant difference was found in the level of external self-confidence in terms of dealing with a different sports branch. Though, in terms of general selfconfidence scores, the level of general self-confidence of the participants' dealing with a different sports branch differed significantly $(p<0,05)$. According to these findings, we can say that male participants have higher inner and external selfconfidence than female participants, dealing with different sports branches increases the level of inner self-confidence and doing sports can positively contribute to the self-confidence level of physically disabled individuals.

Keywords: sitting volleyball, self-confidence

\footnotetext{
${ }^{1}$ Muş Alparslan Üniversitesi, Türkiye, https://orcid.org/0000-0003-4489-9671

2 Muş Alparslan Üniversitesi, Türkiye

Atıf / Citation: Yılmaz, A. ve Kırımoğlu, H. (2020). Oturarak Voleybol Oyuncularının Öz Güven Düzeylerinin Tespiti. Kastamonu Education Journal, 28(1), 286294. doi:10.24106/kefdergi.3564
} 


\section{Extended Abstract}

Purpose of study: Among the sports branches of individuals with physical disabilities, there is also seated volleyball. Seated volleyball game is an adapted form of volleyball game for physically handicapped individuals. The purpose of both volleyball and seated volleyball bears a resemblance to each other (Kalbli, 2007). In volleyball, players are divided into classes from the lowest to the highest according to their movement abilities. The lowest one is $C$ and the highest one is $\mathrm{A}$. "C" class players are those with loss of limb above the elbow or knee, neurological damage resulting in severe muscle weakness. "B" class players are those with loss of limb below the elbow or knee, neurological damage resulting in severe muscle weakness. " $\mathrm{A}$ " class players are those with loss of hand or foot, neurological or other physical injuries resulting in minimal muscle weakness or limited mobility. Minimal physical disability criteria apply. Seated volleyball game is also known as the right and left, back and forth movement of the players in the sitting position without interrupting their contact with the ground, and it is a suitable game for those with amputation. In addition, it is an activity that provides both social and physical benefit. The game includes elements such as technique, tactic and mentally high-level skills. In addition to this, sports offer the opportunity of success for disabled individuals and enables them to socialize with others in overcoming the difficulties of disability and is a concept that brings joy, happiness, personality development and self-confidence (Zergen, 2008; Erdemir et al., 2009; Kabasakal, 2007; Çevik, 2013; Esatbeyoğlu, 2016). The concept of self-confidence is explained in many ways. According to Bandura (1989), selfconfidence is like an operator who works as a factor that determines how individuals behave. Feltz (1988) states that the concept of self-confidence, which he defines as the belief that an individual will perform a certain activity successfully, is also expressed as self-efficacy and perceived competence. According to Feltz and Lirgg (2001), selfefficacy belief is related to what the individual can do, not what he or she cannot do. Schunk (1985) explained selfefficacy in the form of belief that an individual has developed for his performance in a field. In a study on people with disabilities, they stated that their self-confidence levels decreased before the competition (Pedro et al., 2007). Skučas (2014) conducted a study on self-confidence and stated that people with disabilities have better self-acceptance and psychological adaptations. In this sense, the study was conducted to determine the level of confidence of Turkey Physically Disabled Sports Federation Seated Volleyball Players.

Method: In this research, a general survey model which is one of the descriptive research methods has been applied. The general screening model is described as Karasar (2005) which is a research method which aims to define an existing situation as it exists. The research group consisted of a total of 58 seated volleyball players, of which 52 were male and 6 were female, who has accepted to participate in our study voluntarily from amongst a total of 92 physically handicapped athletes who participate in Physically Handicapped Seated Volleyball Competitions held in Alanya by Turkey Physically Handicapped Sports Federation. "Personal Information Form" developed by researchers and "Self Confidence Scale Form" developed by Akın (2007) were used. The participants were compared in terms of self-confidence levels, gender, whether they engage in a different sports branch or not, license age, income levels, number of siblings. The Self-Confidence Scale is a 5-point Likert-type scale consisting of 33 items and 2 sub-dimensions. The internal consistency reliability coefficients of the scale were .83 for the whole scale, .83 for the internal selfconfidence factor and .85 for the external self-confidence factor. The test-retest reliability coefficient of the scale was .94 for the whole scale, .97 for the internal self-confidence, .87 for the external self-confidence, and the item-total test correlations ranged from .30 to .72 .

Finding and Result: According to the data obtained, it is determined that the self-confidence levels of the players do not have a statistically significant difference in terms of number of siblings, perceived income level, license age, while there is a significant difference between the participants' gender and the mean of internal self-confidence levels. A significant difference was found between the participants' gender and the mean of external self-confidence levels. In terms of engaging in a different sports branch of the participants, the level of internal self-confidence of those engaging in a different sports branch was found to be significantly higher than the ones who did not engage in a different sports branch. Despite this, no significant difference was found in external self-confidence levels in terms of engaging in a different sports branch. However, in terms of general self-confidence points, the overall self-confidence level of the participants engaging in a different sports branch showed a significant difference compared to those who did not engage in a different sports branch. As a result of our research, we can say that male participants who play seated volleyball have higher internal and external self-confidence compared to female participants; that engaging in a different sports branch increases internal self-confidence level and that playing sports may provide positive contribution to self-confidence level in physically handicapped individuals. It is thought that it will contribute to the literature as there is not enough study on the athletes playing seated volleyball in the field literature. 


\section{Giriş}

Spor, tüm insanlar için sağlığın korunması, sosyalleşmenin gerçekleşmesi, psikolojik olarak iyi olma halinin ve mutlu bir yaşamın sağlanması, korunması ve sürdürülmesi için gerekli ve önemlidir. Sporun engelli bireyler için ise ayrıca önemi vardır. Çünkü yaşamın her alanında birçok engelle karşılaşmakta ve karşılaştıkları bu engellerle başa çıkmaları gerekmektedir. Bu manada spor engelli bireylerin yaşama tam katıımlarını sğlamaya, bağımsız yaşama becerilerini kazanmalarına ve ekonomik olarak kenilerini idame ettirmelerine katkı sağlamakla birlikte gelişimsel özellikleri üzerinede etkileri vardır.

Spor; engellilerin toplumla bütünleşmesini sağlayan en önemli faaliyetlerden biridir. Engelli bireylerin, engel durum ve derecesine göre sınıflandırılmış, çeşitli spor branşları mevcuttur. Bu sporlar bedensel engellilerin koordinasyon, denge, bağımsız hareket becerileri kazanmalarına ve verimli zaman geçirmelerine yardımcı olmaktadır. Spor ile bireyler çevreden gelecek herangi bir zarar korkusunun önlenmesine ve bireylerin daha güvenli bağımsız yaşam sürmeleri açısından da katkı sağlamaktadır (Maggill, 1980; Margens, 1990; Civan, 2012). Spor yapan kişinin kendisine olan güveni daha fazla, çevresi ile uyumu daha iyi, ruhsal sağlığı daha dengeli ve düzenlidir (illhan, 2010). Sporun olumlu etkilerini normal gelişim gösteren bireyler kadar engelli bireyler üzerinde de gözlemlenmektedir. Sporun etkinlikleri engelliler için toplumsal bir deneyim olmanın yanında sporun kendi ortamı içindeki bireyleride farklı biçimlerde etkilemekte ve tüm gelişimsel boyutlarına etki etmektedir (Tekkurşun ve ark. 2018).

Kişilerin sahip oldukları kısıtlama ve engeller "engel türleri" adı altında dörde ayrılır. Bu engel türleri zihinsel engellilik, işitme engelliliği, görme engelliliği ve bedensel engelliliğidir (Demir ve İlhan, 2019). Bedensel engellilik, hastalıklar, kazalar ve genetik problemler nedeniyle kas, iskelet ve eklemlerin işlevlerini yerine getirmemesi sonucunda meydana gelen hareket ile ilgili yetersizlikler olarak tanımlanmaktadır. (Özyürek, 1982). Engelli sporlarında en önemli özellik, sporcuların engel türüne ve fonksiyonel düzeylerine göre sınıflandırılmaları ve aldıkları puanlarla yarışmalara katılabilmeleridir (Ergun ve Bayramlar, 2011). Dünya Sağılı Örgütü (DSÖ) İşlevsellik, Yetiyitimi ve Sağlığın Uluslararası Sınıflandırması (ICF) sistemine göre; fiziksel engel; belli organlardaki işleyişte meydana gelen büyük ölçüdeki defekt, limitasyon veya görevini yerine getirememeyle birlikte normal şekilde yürütülen hareketleri ve böylece yaşamın farklı alanlardaki işleyişini engelleyen durum olarak tanımlanmıştır (DSÖ, 2001).

Bedensel engelli bireylerin yaptığı spor branşları arasında oturarak voleybol da yer almaktadır. Oturarak voleybol oyunu, bedensel engelli bireyler için voleybol oyununun uyarlanmış şeklidir. Hem voleybol hem de oturarak voleybol oyununun amacı birbiriyle benzerlik göstermektedir (Kalbli, 2007). Voleybolda, oyuncular hareket yetilerine göre en düşükten en yükseğe sınıflara ayrııır. En düşük $C$, en yüksek olan A'dır. "C" sınıfı oyuncuları; diz üstü veya dirsek amputasyonu olanlar, ciddi flask evre, kas zayıflı̆ıyla sonuçlanan nörolojik bozukluk. "B" sınıfı oyuncuları dirsek veya diz altı amputasyonu olanlar, ciddi flask evre, kas zayıflığıyla sonuçlanan nörolojik bozukluk. "A" sınıfı oyuncuları, el veya ayak eksiklikleri, az seviye kas zayıflı̆̆ veya kısıtlı hareket yetisiyle sonuçlanan nörolojik veya diğer fiziksel yaralanmaları içermektedir. Minimal bedensel engellilik kriterleri geçerlidir. Oturarak voleybol oyununda oyuncular otururma pozisyonunda zeminle temaslarını kesmeden sağa ve sola, ileri ve geri doğru hareket etmeleri olarak da adlandırılan ve amputasyonu olanlar için oldukça uygun bir oyundur. Bunun yanında, toplumsal fayda sağlarken aynı zamanda fiziksel olarakta fayda sağlayan bir etkinliktir. Oyun teknik, taktik ve zihinsel olarak üst düzey beceri gibi unsurları içermektedir. Bunun yanında spor engelli bireyler için başarı duygusunu yaşamalarına fırsat sunan, engelliliğin vermiş olduğu zorlukları aşmalarında ve başkaları ile sosyalleşmelerini sağlamakla birlikte neşe, mutluluk duygusu, kişilik gelişimi, kendine güven duygusunu kazandıran bir kavramdır (Zergen, 2008; Erdemir ve ark., 2009; Kabasakal, 2007; Çevik, 2013; Esatbeyoğlu, 2016).

Özgüven kavramı birçok şekilde açıklanmıştır. Bandura'ya (1989) göre özgüven, bireylerin nasıl davranacaklarını belirleyen bir faktör olarak yeteneklerini çalıştıran bir operatör gibidir. Feltz (1988) bireyin belli bir aktiviteyi başarılı bir biçimde yerine getireceği yönündeki inancı şeklinde tanımladığı özgüven kavramının öz- yeterlilik ve algılanan yeterlilik şeklinde de ifade edildiğini belirtmektedir. Feltz ve Lirgg'e (2001) göre öz-yeterlilik inancı bireyin ne yapamadığı ile ilgili değil ne yapabileceğiyle ilgili düşünceleri ile ilgilidir. Schunk'a (1985) göre ise öz yeterlilik bireyin bir alandaki performansına yönelik geliştirmiş olduğu inancı olduğu şeklinde açıklamıştır. Engelli bireyler üzerine yapılan bir araştırmada, özgüven düzeylerinin yarışma öncesinde azaldığını belirtmişlerdir (Pedro ve ark., 2007). Skučas (2014) tarafından özgüven üzerine yapılan çallışmada engelli bireylerin kendilerini kabuletme ve psikolojik adaptasyonlarının daha iyi olduğunu belirtmiştir. Bu manada çalışma; Türkiye Bedensel Engelliler Spor Federasyonu, Oturarak Voleybol oyuncularının özgüven düzeylerini tespit etmek amacıyla gerçekleştirilmiştir. 


\section{Yöntem}

\section{Araştırmanın modeli}

Bu araştırmada betimsel araştırma yöntemlerinden biri olan, genel tarama modeli uygulanmıştır. Genel tarama modeli var olan bir durumu, var olduğu şekli ile tanımlamayı amaçlayan araştırma metodu olarak Karasar (2005) açıklanmaktadır.

\section{Araştırma grubu}

Araştırmanın evreni, Türkiye Bedensel Engelliler Spor Federasyonu tarafında Alanya ilinde düzenlenen Bedensel Engelliler Oturarak Voleybol Müsabakalarına katılan genel toplamda 92 bedensel engelli sporcu oluşturmaktadır. Örneklem grubunu çalışmamıza gönüllü olarak katılmayı kabul eden, 52'si erkek, 6'sı kadın olmak üzere toplamda 58 oturarak voleybol oyuncusundan oluşmuştur.

\section{Veri toplama araçları}

Araştırmacılar tarafından geliştirilen "Kişisel Bilgi Formu" ve Akın (2007) tarafından geliştirilen "Öz Güven Ölçeği" kullanılmıştır. Katıımcıların Öz güven düzeyleri; cinsiyet, farklı bir spor branşı yapıp yapmadığı, lisans yaşları, gelir düzeyleri, kardeş sayıları açısından incelenmiştir.

Özgüven Ölçeği, 33 madde ve 2 alt boyuttan oluşmakta olup 5'li Likert tipi bir ölçektir. Ölçek likertlemesi hiçbir zaman, nadiren, bazen, genellikle, her zaman ifadeleri kullanılmıştır. Ölçeğin iç tutarlıık güvenirlik katsayıları ölçeğin tümü için .83 , iç özgüven faktörü için .83 ve dış özgüven faktörü için .85 olarak bulunmuştur. Ölçeğin test-tekrar test güvenirlik korelasyon katsayılarının ölçeğin bütünü için .94, iç özgüven için .97 , dış özgüven için .87 olduğu tespit edilmiştir. Ölçekten alınabilecek en yüksek puan 165, en düşük puan ise 33'dür. Ölçekte olumsuz madde bulunmamaktadır. Ölçekten alınan yüksek puan, yüksek düzeyde özgüveni göstermektedir. Özgüven Ölçeği'nin puanlanmasında toplam puan ve alt ölçek puanları elde edilmektedir. İç özgüven alt boyutu 17 madde olup bireyin kendini sevmesi, tanıması, açık hedefler belirlemesi, bilmesi gibi özelliklerini değerlendirmektedir. Dış özgüven alt boyutu ise 16 maddeden olup bireylerin dış çevre ve sosyal yaşamlarına yönelik özgüvenleriyle ilişkilidir (Akın, 2007).

\section{Verilerin analizi}

Araştırmanın katılımcılarından elde edilen verilerin analizinde SPSS 22.0 istatistik paket programı kullanılmıştır. Verilerin normallik sınaması One-Sample Kolmogorov-Simirnov test ile yapılmış olup, normal dağılım göstermediğinden veriler hesaplanırken, non-parametrik testlerden Mann Whitney $U$ ve Kruskal Wallis Testi kullanılmıştır. Bu çalışmada istatistiksel anlamlıık düzeyi 0,05 olarak kabul edilmiştir.

\section{Bulgular}

Tablo 1. Bireylerin Cinsiyetleri İle Özgüven Düzeyleri Farklılığına İlişkin Mann Whitney U Testi

\begin{tabular}{llllll}
\hline & Cinsiyet & $\mathrm{n}$ & Sıra Ort. & $\mathrm{U}$ & $\mathrm{p}$ \\
\hline İç özgüven & Erkek & 52 & 31,70 & 237,500 &, $03^{*}$ \\
& Kadın & 6 & 15,92 & & \\
Dış özgüven & Erkek & 52 & 30,97 & 232,500 &, $04^{*}$ \\
& Kadın & 6 & 16,75 & & \\
Toplam & Erkek & 52 & 30,93 & 230,500 &, 05 \\
Özgüven & Kadın & 6 & 17,08 & & \\
\hline
\end{tabular}

Katılımcıların cinsiyet değişkeni açısından iç özgüven ve dış öz güven alt boyutları puan ortalamaları arasında anlamlı farklılık tespit edilmiştir $(p<0,05)$. Katılımcıların toplam öz güven düzeylerinde ise anlamlı farklıık tespit edilmemiştir $(p>0,05)$. 
Tablo 2. Bireylerin Diğer Bir Spor Branşı Yapmaları İle Özgüven Düzeyleri Farklılığına İlişkin Mann Whitney U Testi

\begin{tabular}{llllll}
\hline & Branş & $\mathrm{n}$ & Sıra Ort. & $\mathrm{U}$ & $\mathrm{p}$ \\
\hline \multirow{2}{*}{ İç özgüven } & Voleybol & 10 & 40,10 & 346,0 &, $02^{*}$ \\
& Diğer & 48 & 27,29 & & \\
Diş özgüven & Voleybol & 10 & 38,80 & 333,0 &, 05 \\
& Diğer & 48 & 27,56 & & \\
Toplam & Voleybol & 10 & 40,00 & 345,0 &, $03^{*}$ \\
Özgüven & Diğer & 48 & 27,31 & & \\
& & & & &
\end{tabular}

Katılımcıların branş değişkenine göre toplam özgüven toplam puan ve iç özgüven alt boyutu düzeylerinde anlamlı farklılık tespit edilmiştir $(p<0,05)$. Katılımcıların dış özgüven alt boyutunda ise anlamlı farklılık tespit edilememiştir $(p>0,05)$.

Tablo 3. Bireylerin Lisans Yaşları Ille Özgüven Düzeyleri Farklılığına İlişkin Kruskall Wallis Testi

\begin{tabular}{lclrlcl}
\hline & Lisans yaşı & $\mathrm{n}$ & \multicolumn{1}{c}{ Sıra Ort. } & Sd & Kruskal-Wallis & $\mathrm{p}$ \\
\hline iç özgüven & $1-3$ yıl & 43 & 30,16 & & & \\
& $4-6$ yıl & 9 & 22,11 & 2 & 2,643 & $0,2^{*}$ \\
\multirow{5}{*}{ Dış özgüven } & $7-9$ yıl & 6 & 35,83 & & & \\
& $1-3$ yıl & 43 & 30,55 & & & \\
& $4-6$ yıl & 9 & 20,67 & 2 & 3,340 & $0,1^{*}$ \\
Toplam & $7-9$ yıl & 6 & 35,25 & & & \\
Özgüven & $1-3$ yıl & 43 & 30,17 & & & $0,2^{*}$ \\
& $4-6$ yıl & 9 & 21,83 & 2 & 2,862 & \\
& $7-9$ yıl & 6 & 36,17 & & & \\
\hline
\end{tabular}

Katılımcıların lisans yaşı değişkenine göre toplam öz güven, iç özgüven ve dış özgüven alt boyutlarında anlamlı farklılık tespit edilmiştir $(p>0,05)$.

Tablo 4. Bireylerin Gelir Düzeyleri İle Özgüven Düzeyleri Farklılığına İlişkin Kruskall Wallis Testi

\begin{tabular}{lllllll}
\hline & Gelir düzeyi & $\mathrm{n}$ & Sıra Ort. & $\mathrm{Sd}$ & Kruskal-Wallis & $\mathrm{p}$ \\
\hline \multirow{3}{*}{ İ̧ özgüven } & Düşük & 8 & 28,56 & & & \\
& Orta & 43 & 30,03 & 2 & 0,189 & 0,9 \\
& Yüksek & 7 & 27,29 & & & \\
& Düşük & 8 & 26,25 & & & 0,6 \\
Diş özgüven & Orta & 43 & 30,72 & 2 & 0,877 & \\
& Yüksek & 7 & 25,71 & & & 0,7 \\
& Düşük & 8 & 27,62 & & & \\
Toplam & Orta & 43 & 30,42 & 2 & 0,527 & \\
Özgüven & Yüksek & 7 & 26,00 & & & \\
\hline
\end{tabular}

Katılımcıların gelir düzeyi değişkeni açısından toplam öz güven, iç özgüven ve dış özgüven alt boyutlarında anlamlı farklılık tespit edilememiştir $(p>0,05)$. 
Tablo 5. Bireylerin Kardeş Sayıları İle Özgüven Düzeyleri Farklılı̆ına Illişkin Kruskall Wallis Testi

\begin{tabular}{|c|c|c|c|c|c|c|}
\hline & Kardeş sayısı & $\mathrm{n}$ & Sira Ort. & $\mathrm{Sd}$ & Kruskal-Wallis & $p$ \\
\hline \multirow{3}{*}{ İç özgüven } & Kardeşi Yok & 6 & 33,75 & \multirow{3}{*}{3} & \multirow{3}{*}{2,989} & \multirow{3}{*}{$0,3^{*}$} \\
\hline & 1-3 Kardeş & 30 & 31,93 & & & \\
\hline & 4-6 Kardeş & 15 & 26,63 & & & \\
\hline \multirow{5}{*}{ Dış özgüven } & 7-9 Kardeş & 7 & 21,57 & \multirow{4}{*}{3} & \multirow{4}{*}{2,505} & \multirow{4}{*}{$0,4^{*}$} \\
\hline & Kardeşi Yok & 6 & 31,92 & & & \\
\hline & 1-3 Kardeş & 30 & 32,85 & & & \\
\hline & 4-6 Kardeş & 15 & 27,60 & & & \\
\hline & 7-9 Kardeş & 7 & 21,43 & \multirow{5}{*}{3} & \multirow{5}{*}{2,866} & \multirow{5}{*}{$0,4^{*}$} \\
\hline \multirow{4}{*}{$\begin{array}{l}\text { Toplam } \\
\text { Özgüven }\end{array}$} & Kardeşi Yok & 6 & 32,67 & & & \\
\hline & 1-3 Kardeş & 30 & 31,98 & & & \\
\hline & 4-6 Kardeş & 15 & 27,70 & & & \\
\hline & 7-9 Kardeş & 7 & 21,07 & & & \\
\hline
\end{tabular}

Katılımcıların kardeş sayısı seğişkenine göre toplam öz güven, iç özgüven ve dış özgüven alt boyutlarında anlamlı farklılık tespit edilmiştir $(p>0,05)$.

\section{Tartışma ve Sonuç}

Bu araştırma, Türkiye Bedensel Engelliler Spor Federasyonu, oturarak voleybol oyuncularının özgüven düzeylerini tespit etmek amacıyla gerçekleştirilmiştir. Yapılan literatür taramasında çalışmamızla aynı özellikte çalışmaya rastlanmadığından benzer çalışmalar ile tartışılacaktır. Araştırma bulgularında katılımcıların cinsiyet değişkeni açısından iç özgüven ve dış öz güven alt boyutlarında anlamlı farklılığın çıktığı tespit edilmiştir. Bunun yanında katılımcıların cinsiyetleri ile toplam özgüven puanları arasında anlamlı farklılı̆ın çıkmadığı tespit edilmiştir. Bu manada, erkeklerin kadınlara göre daha yüksek iç ve dış özgüven düzeyine sahip olduğunu buna karşın genel öz güven düzeylerinde erkekler ve kadınların aynı özgüven düzeyine sahip olduğu ifade edilebilir. Can ve Kaçay (2016) yılında yapmış oldukları çalışmada özgüven duygusunda cinsiyet açısından anlamlı bir farklılık bulunmazken, dış özgüven duygusunda cinsiyet açısından kadın sporcuların erkek sporculara göre daha yüksek dış özgüven duygusuna sahip olduklarını belirtmişlerdir. Buda araştırmamızın özgüven ve iç öz güven alt boyutunda farklı çıkmasına rağmen, dış öz güven alt boyutu sonucumuzu destekler niteliktedir. Mutlu ve ark. (2016) yılında yapmış oldukları çalışmada cinsiyet değişkeni açısından öz güven ve alt boyutlarında anlamlı farklılık çıktığını belirtmişlerdir. Bostancı ve ark. (2018) yapmış oldukları çalışmada ise sporcuların toplam özgüven ve alt boyutlarında (iç-dış) cinsiyetlerine göre bir farklılık olmadığını belirtmişlerdir. Bu da çalışmamızı kısmen destekler niteliktedir. Cinsiyet açısından yapılan çalışmaların bulgularının farklı çıkmasının çalışmamızda engelli sporcular ile yapılmış olmasının etkisi olduğunu söyleyebiliriz. Araştırmamızın bir diğer bulgusunda, katılımcıların brans değişkenine göre özgüven düzeyleri ve iç özgüven düzeyleri ortalamaları arasında anlamlı farklılık çıkarken, dış özgüven alt boyutunda anlamlı farklılık bulunamamıştır. Özbek (2017) yılında yapmış olduğu çalışmada farklı branşlar ve sedanter öğrencilere göre hem iç özgüven ve dış özgüven seviyelerinin daha yüksek olduğunu bildirmiştir. Mevcut araştırma çalışmamızı destekler niteliktedir. Can ve Kaçay (2016) farklı branşlarda özgüven düzeyi ve alt boyutlarında anlamlı bir farklıık bulunmadığını belirtmişlerdir. Araştırmamızın diğer değişkeni olan lisans yaşına göre ise iç özgüven alt boyutu, dış özgüven alt boyutu ve genel özgüven düzeyleri arasında anlamlı farklılık çıkmamıştır. Can ve Kaçay (2016) yapmış olukları çalışmada özgüven ve iç özgüven düzeyinde anlamlı farklılık çıkmazken; dış özgüven düzeyinde spor yılı açısından anlamlı bir farklılık bulunmuştur. Mutlu ve ark (2016) tarafından yapılan çalışmada da spor yapma süreleri açısından anlamlı bir farklılığa rastlamamışlardır. Yapılan araştırmalarla da spor ile uğraşmanın engelli bireylerin sosyalleşmelerini, kişilik gelişimini ve özgüven duygusunu arttırdığ (Graham ve Reid 2000; Guidetti ve ark 2009; Wiśniowska ve ark., 2012) belirtilmiştir. Araştırmalar çalışmamızı destekler niteliktedir. Araştırmamızın diğer değişkeni olan gelir seviyeleri ile iç özgüven alt boyutu, dış özgüven alt boyutu ve genel özgüven düzeyleri arasında anlamlı farklılık tespit eilememiştir. Bu manada, gelir seviyesinin özgüven düzeyine etki etmediğini söyleyebiliriz. Araştırmada katılımcıların kardeş sayıları i̧̧ özgüven alt boyutu, dış özgüven alt boyutu ve genel özgüven düzeyleri arasında anlamlı farklılık tespit edilememiştir. araştirmaya katilan katilimcilar açisindan kardeşe sahip olmanın öz güven düzeyini etkilemediği söylenebilir. 
Araştırmamızın sonucunda, oturarak voleybol oynayan erkek katılımcıların, kadın katılımcılara oranla daha yüksek iç ve dış özgüvene sahip olduklarını; farklı spor branşı ile uğraşmanın iç öz güven düzeyini arttırdığını ve spor yapmanın bedensel engelli bireylerde öz güven düzeyine pozitif katkı sağlayabileceğini söylenebilir. Literatürde spora katılımın bireylerin boyun eğici davranışlarını (Bozkurt, Demir ve Cicioğlu, 2019; Özbek, Yoncalık ve Alıncak, 2017; Güvendi ve Hazar, 2016) ve çağın hastalığı dijital oyuna katılımı (Demir ve Cicioğlu, 2019; Hazar vd., 2017; Güvendi vd., 2019) azalttığı; motivasyon (Kartal vd., 2017; Türksoy vd., 2016; Tekkurşun, vd., 2018; Illhan, 2010; Güvendi ve illhan, 2017; Demir ve Cicioğlu, 2018), sosyalleşme (illhan, 2008a; illhan, 2008b), özerklik (Filazoğlu, vd., 2015; Gönül, vd., 2018), tutum (Gülünay, vd., 2017; Kaya vd., 2018) ve farkındalık düzeyini (Kırımoğlu vd., 2016; Esentürk vd., 2015; Kemeç, Demir ve Koç, 2018) arttırdığı belirtilmektedir. Bu bağlamda Araştırmanın literatürde oturarak voleybol oynayan sporcular üzerine yeterli çalışma bulunmadığından literatüre katkı sağlayacağı düşünülmektedir.

\section{Kaynakça}

Akın, A. (2007). Özgüven Ölçeğinin Geliştirilmesi ve Psikometrik Özellikleri. Abant İzzet Baysal Üniversitesi Eğitim Fakültesi Dergisi, 2:165-175.

Bandura, A. (1989). Sixtheories of child development. Annals of Child Development, 6,1-60.

Bostancı, Ö., Karaduman, E., \& Şebin, K. (2018). Dağcıların Özgüven Seviyelerinin Çeşitli Değişkenler Açısından İncelenmesi. Beden Eğitimi ve Spor Bilimleri Dergisi, 20(3), 144-153.

Bozkurt, T. M., Demir, G. T., \& Cicioğlu, H. i. (2019). Spor Lisesi Öğrencilerinin Boyun Eğici Davranış Düzeyleri. Gazi Beden Eğitimi ve Spor Bilimleri Dergisi, 24(2), 89-99.

Can, Y., \& Kaçay, Z. (2016). Sporcu kimlik algısı ile cesaret ve özgüven duyguları arasındaki ilişkilerin incelenmesi. Journal of Human Sciences, 13(3), 6176-6184. doi:10.14687/jhs.v13i3.4353.

Civan, A., Özdemir, I., Taş, I.., \& Çelik, A. (2012). Bedensel engelli ve engelli olmayan tenis sporcularının durumluk ve sürekli kaygı düzeylerinin karşılaştırılması. Selçuk Üniversitesi Beden Eğitimi ve Spor Bilim Dergisi, 14(1), 83-87.

Demir, G. T. \& Cicioğlu, H. İ., (2019) Fiziksel Aktiviteye Katilim Motivasyonu Ille Dijital Oyun Oynama Motivasyonu Arasindaki İlişkinin İncelenmesi, Spormetre Beden Eğitimi ve Spor Bilimleri Dergisi

Demir, G. T., \& Cicioğlu, H. I. (2018). Motivation Scale for Participation In Physical Activity (MSPPA): A study of validity and reliability Fiziksel Aktiviteye Katılım Motivasyonu Ölçeği (FAKMÖ): Geçerlik ve güvenirlik çalışması. Journal of Human Sciences, 15(4), 2479-2492.

Demir, G. T., \& İlhan, E. L. (2019). Spora Katılım Motivasyonu: Görme Engelli Sporcular Üzerine Bir Araştırma. Gaziantep Üniversitesi Spor Bilimleri Dergisi, 4(1), 157-170.

Erdemir, I., Tekin, H.A., Savucu, Y., \& Tüfekçioğlu, E. (2009). Birinci ve ïkinci Lig Tekerlekli Sandalye Basketbolcularında Performansı Etkileyen Faktörler. F.Ü.Sağ.Bil.Tıp Dergisi, 23(2), 85 - 89.

Ergun, N., \& Bayramlar, K. K. (2011). Engelsiz Bir Yaşam İçin Egzersiz ve Spor. Ankara: Merdiven Tanıtım.

Esatbeyoğlu, F. (2016). Yeti Yitimi Olan Gençler için Fiziksel Aktivitenin Önemi. Baran, A. G. ve Çakır, M. (Edt.) İnterdisipliner yaklaşımla gençliğin umudu toplumun beklentileri. Hacettepe Üniversitesi Yayınları. S. 261-282.

Esentürk O.K., Koç Y., Yarımkaya E., İlhan E.L., (2015). University students awareness levels on the effects of sport in mentally retarded individuals, III. International Exercıse snd Sport Psychology Congress, İstanbul, Turkey, 100.

Feltz, D. L. (1988). Self-confidence and sports performance. Exercise and Sport Sciences Reviews, 16(1), 423- 458.

Feltz, D. T. \& Lirgg, C. D. (2001). Self Efficacy Beliefs on Athletes, Teamandco Aches. (In R. N. Singer, H. A. Hausenblas, ve C. Janelle (Eds.). Handbook of sport psychology (pp.340-361). New York: John Wiley\&Sons

Filazoğlu, G., Kırımoğlu, H., Öz, A.Ş. \& Illhan, E.L. (2015). The effects of physical education and sports on the self-concept of the children with mild mental disabilities, International Journal of Science Culture and Sport, 3(3), 55-72.

Gönül, T. D., İbrahim, C. H., Levent, I. E., \& Zekihan, H. (2018). Examination of Friend Related Autonomy in The Participation of Physical Education Teacher Candidates in The Exercise. Ovidius University Annals, Series Physical Education and Sport/Science, Movement and Health, 18(2 S1), 452-458. 
Graham A, Reid G, 2000. Physical fitness of adults with an intellectual disability: a 13-year follow-up study. Res Q Exerc Sport. 71(2), 152-61.

Guidetti L, Franciosi E, Emerenziani GP, Gallotta MC, Baldari C, 2009. Assessing basketball ability in players with mental retardation. Br J Sports Med. 43(3), 208-12.

Gülünay, Y.İ., Kayışoğlu, N.B., İlhan E.L. (2017). Beden eğitimi öğretmeni adaylarının zihinsel engelli çocuklara yönelik tutumlarının çeşitli değişkenlere göre incelenmesi, 15. Uluslararası Spor Bilimleri Kongresi Bildiri Kitabı, 1540.

Güvendi, B. \& Hazar, M. (2016). Playfulness, perceived stress and coping with stress approaches in teacher candidates in various departments. Journal of Human Sciences, 13(3), 5796-5806.

Güvendi, B., Demir, G. T., \& Keskin, O. (2019). Ortaokul öğrencilerinde Dijital Oyun Bağımlılığı ve Saldırganlık, OPUS Uluslararası Toplum Araştırmaları Dergisi,11(18).

Güvendi, B., Illhan E. L. (2017). Effects of adapted physical activity applied on intellectual disability students toward level of emotional adjustment, self-managingand the socialization: Parent and teacher interactive research, International Journal of Human Sciences, 14(4), 3880-3894.

Hazar, Z., Demir, G. T., Namlı, S. \& Türkeli, A., (2017). Ortaokul Öğrencilerinin Dijital Oyun Bağımlılığı ve Fiziksel Aktivite Düzeyleri Arasındaki IIlşkinin İncelenmesi. Niğde Üniversitesi Beden Eğitimi ve Spor Bilimleri Dergisi, 11(3), 320 332.

İlhan, E. L. (2010). Hareketsiz Yaşamlar Kültürü ve Beraberinde Getirdikleri. Milli Prodüktivite Merkezi Verimlilik Dergisi, $3,195-210$

İlhan, L. (2008a). Eğitilebilir zihinsel engelli çocuklarda beden eğitimi ve sporun sosyalleşme düzeylerine etkisi, Kastamonu Eğitim Fakültesi Dergisi, 16(1), 315-324.

İlhan, L. (2008b). Zihinsel engelli çocuklar için beden eğitimi ve sporun genel gelişim süreçleri açısından önemi. Çağdaş Eğitim Dergisi, 33(350), 17-24.

Kabasakal, K. (2007). Zihinsel Engellilik, Zihinsel, Ruhsal, Duygusal Engellilik, Lokomotif Medya, Ünimat Ofset Matbaası, Konya.

Kalbli, K. (2007). Comparative Study on The Serves of Volleyball and Sitting Volleyball Games. Semmelweis University Faculty of Physical Education and Sport Sciences, Hungary, 12th Annual Congress of The Ecss, 11-14 July Jyvaskyla Finland.

Karasar, N. (2005). Bilimsel Araştırma Yöntemleri, Nobel Yayınları. Ankara.

Kartal, Z., Güvendi, B., Türksoy, A., \& Altıncı, E. E. (2017). Takım Sporcularının İmgeleme Kullanımları İle Başari Motivasyonları Arasındaki ilişki. İstanbul Üniversitesi Spor Bilimleri Dergisi, 7(1), 41-53.

Kaya, Ö., Cicicoğlu, H. İ., \& Demir, G. T. (2018). The Attitudes of University Students Towards Sports: Attitude and Metaphorical Perception. European Journal of Physical Education and Sport Science.

Kemeç, D. G., Demir, G. T., \& Selahattin, K. O. Ç. Doktor Adaylarının Zihinsel Yetersizliği Olan Bireylerde Sporun Etkilerine Yönelik Farkındalıkları. Gaziantep Üniversitesi Spor Bilimleri Dergisi, 3(4), 153-168.

Kırımoğlu, H., Yılmaz, A., Soyer, F., Beyleroğlu, M. \& İlhan, E. L. (2016). Zihinsel engelli bireylerde sporun etkilerine yönelik farkındalık: beden eğitimi öğretmen adayları üzerine bir araştırma. Niğde Üniversitesi Beden Eğitimi ve Spor Bilimleri Dergisi, 10(1), 80-88.

Maggill, R. A. (1980). Motor Learning. 66-124, Wm. C. Brown Comp. Pub. USA.

Martens, R. ( 1990). Seccessful Coaching. Second Edition, Leisure Press, Champaign, Ilinois.

Mutlu, T. O., Öntürk, Y., Karafil, A. Y., Zorba, E., Bingöl, E. \& Kaya, K. (2016). Analysıs on The Self-Confıdence Perceptıons of Unıversıty Students Playıng Tennıs in Sports. General Informatıon about Sstb Journal, 18, 17-28.

Özbek, S., Yoncalık, M. T. \& Alıncak, F. (2017). Sporcu ve Sedanter Lise Öğrencilerinin Özgüven Düzeylerinin Karşılaştırılması (Kırşehir ilii Örneği). Gaziantep Üniversitesi Spor Bilimleri Dergisi, 2(3), 46-56. 
Özbek, S., Yoncalık, M. T. \& Alıncak, F. (2017). Sporcu ve Sedanter Lise Öğrencilerinin Özgüven Düzeylerinin Karşılaştırılması (Kırşehir ili Örneği). Gaziantep Üniversitesi Spor Bilimleri Dergisi, 2(3), 46-56.

Özyürek, M. (1982). Normal Öğrencilerle Birlikte ve Ayrı Eğitilen Ortopedik Arızalı Öğrencilerde Benlik Kavramı ve Denetleme Odağı. Ankara Üniversitesi Eğitim Fakültesi, Ankara, Yayınlanmamış Doçentlik Tezi.

Pedro, L. F., Chatzisarantis N. \& Pedro M.C.M.J. (2007). Precompetitive Anxiety and Self-Confidence in Athletes with Disability. Perceptual and Motor Skills, 105 (1).

Schunk, D. H. (1985). Self-Efficacy and Classroom Learning. Psychology in the Schools, 22:208-223.

Skučas, K. (2014). Athletıc identity and self-esteem of wheelchair basketball players. Baltic Journal of Sport \& Health Sciences,95(4).

Tekkurşun, D. G., İlhan, E. L., Esentürk, O. K., \& Adnan, K. A. N. (2018). Engelli Bireylerde Spora Katılım Motivasyon Ölçeği (Eskmö): Geçerlik ve Güvenirlik çalışması. Spormetre Beden Eğitimi ve Spor Bilimleri Dergisi, 16(1), 95106.

Turksoy, A., Güvendi, B., Sahin, M., \& Korkmaz, M. (2016). Determınıng The Relatıonshıp Between Self-Effıcacy, Perceptıon of Success and Motıvatıon in Junıor Natıonal Wrestlıng Team Athletes Güreş Yıldız Milli Takım Sporcuların Öz-Yeterlik, Başarı Algısı Ve Güdülenme Düzeylerinin Belirlenmesi. International Refereed Academic Journal of Sports, 21, 16-26.

World Health Organization (2001). The International Classification of Functioning, Disability and Health (ICF). Geneva: WHO. http://www.who.int/classifications/icf/en/

Wiśniowska, M., Tasiemski, T., Bauerfeind, J. (2012). Athletic Identity Assessment in Disabled Sitting Volleyball Players. Physiotherapy / Fizjoterapia, 20(1).

Zerger, M. (2008). A Study of Movement in Sitting Volleyball. A Thesis Submitted To The Gradua The Faculty in Partıal Fulfillment of The Requirements for The Degree of Master of Science Kinesiology and Health Studies Unıversity of Central Oklohoma Edmond. 